of the hand are inactive, there is no object in an arthrodesis of the shoulder.

I perform the operation by the anterior incision commonly, used for excision of the shoulder-joint. The hinierus should be fixed in abduction and internal rotation -so that the hand can be brought to the mouth.

It is very rare for me to perform arthrodesis of the knee. It is an operation which, if not performed early, gives an admirably firm limb, and I have patients who go about their work contentedly, with a stiff knee and ankle; others, however, regret the day on which they consented to this operation. This regret is merely due to inconvenience. The limb, they say, is always in the way and in evidence. Where money permits, a lock calliper fills every indication, and can be used for walking in extension or sitting in Hexion.

Arthrodesis, in my opinion, is quite unsuitable for hip, wrist, or elbow. At the elbow because the removal of skin and fixation of forearm at an acute angle does what is desired. At the wrist the usefulness of the fingers depends on the presence of some degree of co-ordination of inovement, which means that both extensors and flexors must be acting and controlling each other. If there be power in the muscles the hand can always be made useful hy means other than arthrodesis, and, of course, if the hand is useless the wrist should be left alone.

\section{Trinsplantation of Nerves.}

No discussion of the surgery of paralysis would be complete at the present day without some reference to the traisplantation of nerves. Our present knowledge of regeneration of nerves is such that it-seems entirely reasonable to expect that if the distal end of a paralysed motor nerve be connected by grafting with the proximal end of an active motor nerve, it should result in restoration of conductivity in the paralysed nerve, and of function in the muscles supplied by them. This operation is not new, for Hackenbruch reported a successful case of grafting of the external and internal popliteal nerves for paralysis of all muscles supplied by the former so long ago as 1905.

My friend Spitzy of Graz has published a most interesting series of papers, rumning from 1904 to the present day, in which he has dealt with the subject carefully, both from the experimental and clinical point of view. Nevertheless, I come before you with very slight personal experience of the operation, not sufficient to speak with any authority.

I would put forward with all diffidence a general criticism of reported cases. Many surgeons have performed the operation in a few cases, and have reported a few successes and many failures. Of the failures I shall speak later, but shali first say a word of the successes.

So far as. I have seen reports of successful cases, the procedure has been to perform the operation of nervo tiransplantation, and then fix the limb in a position which woild keep the grafted nerve relaxed. At the same time the muscles have been assiduously massaged, and every means taken to get them into good condition. In this lurks the fallacy that the success, in some instances at any rate, may be due to the muscles having been in a state of functional disability, and not really paralysed at all.

The author's of these reports do not prove to my satisfaction that every means has previously been taken to exclude this possibility. I must remind you of Wittek's case, whicl I have quoted, and of my own many experiences of instances where recovery of power has taken place unexpectedly, but. in absolute accord with the principles we have:discussed.

I by no means intend this criticism to mean that none of these successes are credible, but that they are lacking in scientific value, because sufficient care has not been taken to exclude the fallacy which I have indicated.

I may be charged with lack of enterprise for not having performed the operation, on a series of cases in which 1 have been contented with arthrodesis, after satisfying myself that no recovery is likely to occur in the paralysed group. My answer to this charge is a very simple oneI do not know how to perform the operation with any degrce of accuracy or certainty. Consider a case of paralysis of the muscles supplied by the anterior tibial nerre. A successful neuroplasty demands that the bundle of motor nerves intended for this group of muscles bc isolated from the tiunk of the external popliteal nerve and grafted into an active motor bundlc in the internal popliteal. I speak of bundles in this way, for six ycars ago Spitzy pointed ont that in operating on the anterior crural nerve where it enters the thigh it must be rememberect that all the motor fibres lie in the outer half of the nerve, and all the sensory fibres in the inner half. Stoeffel has recently published a most valuable anatomical research on this subject, in which he has shown that both in the upper and lower limb nerres to groups of muscles-for example, the anterior tibial nerve-can be traced back well up the main trunk as a distinct bundle wrapped in their own sheath. He has shown, too, that in the case of the musculocutaneous nerve in the leg, the motor fibres to the perone1, and the sensory branches can be treated as separate bundles, not only in the trunk of the musculo-cutaneous nerve, but also up into the truuk of the external popliteal nerve.

In the face of sueh anatomical difficulties it is not surprising that the results of nerve transplantation for the treatment of paralysis have been uncertain and disappointing. If Stoeffel, and others working on the same lines, can give us a clear account of the internal topography of nerve trunks, and show us how we can identify with certainty bundles of nerres destined to supply particular groups of muscles, the first step will lrave becn taken towards putting neuroplasty on a sound scientific footing.

The subject of the treatment of polionyelitis is so farreaching that, in spite of this long address, I have only becn able to touch lightly and inadequately upon a few of its many points of interest. It offer's a most fascinating field, full of variety to a surgeon who has patience and enthusiasm. To approach the subject in a spirit of (loubt and pessimism is fatal to success.

\section{A Host-(braduate lerture}

\section{NEUROTIC DYSPEPSIA.}

Defrerey at the London School of

Clinical Medicine.

BY GL'THRIE RANKIN, M.D., F.R.C.P.,

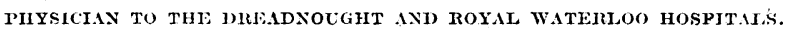

You may remember that a week or two ago wo investigated, a case of gastric disturbance in a man, about whom wo came to the concinsion that he was probably suffering from a local functional condition grafted on to a general state of neurasthenia, sinulating at first sight, in many of the subjective symptoms and the objective signs, an ulcer either of the duodenum or of the pyloric end of the stomach. Though cases of this description are not often seen in this hospital, they are common in private practice, and the more I see of them the more I become convinced! of the necd for caution in arriving at a firm diagnosi; until full opportunity has been afforded of watching the progress of events under the influence of rest, dietary, anc' drugs. This occasion is opportune for bringing to you notico some recent cases coming within my own experience which testify to the need for such an attitude of expectant observation. The classification of functional disorders of the digestive organs is so confused that the difficulties of diagnosis are often very considerable. But, when we come to think of it, the fumotion of any organ can be disturbeci only in one of three ways-by excess, by default, or. by perversion-and, in accordance with this propesition, Professor Robin's suggestion that all dyspepsias - should be grouped under three primary headings, according as they are caused by hyperfunction, hypofunction, or abnormal fermentations, has much to recommend it. While the great bulk of dyspepsias may, in a broad way, be parcelled out into these three varieties. it is obvious that there must be much overlapping of one class of case with another; that a patient may present such a succession of symptoms as would bring him into one category of the disease at one time and into another at another; and that there must be certain secondary groups of the disorder so well marked as 
to justify their allocation to subdivisions of their own. Such a subdivision is, I think, to be found in one class of dyspepsia which we meet with so frequently in persons at or beyond the middle period of life, who belong to the neurasthenic type of humanity. Patients who may be thus elassified present a train of symptoms characteristic enough for easy recognition, the one pitfall of importance being the possibility of mistaking the condition for duodenal ulcer. This mistake probably happens, in the aggregate of cases, more frequently than is suspected. The growing conviction of clinical experience, amounting almost to a certainty, that those symptoms which have been held forth as certain evidence of ulceration on one side or other of the pylorus can bo reproduced almost exactly by functional conditions, should make us hesitate before arriving at over-hasty conclusions.

The outline of the symptomatology of thi: type of dyspepsia is somewhat as follows: The patien is most frequently a man, generally at or past the meridian of life. $\mathrm{He}$ usually comes with a story of impaired digestion eontinuing over some months or even years, but latterly becoming more intense and definite in its manifestations, and giving rise to such recurrent discomfort that his life is rendered wretched. He is mentally depressed, complains of inertia, insomnia; occipital headache, and latterly of loss of fleshi, together with some of the other multifarious evidenees of neuraisthenia. He attributes his decreasing weight to the care he takes to limit his food, because, though his appetite is vigorous, he fears to satisfy it. The pains in his stomach from which he suffers came at first irregularly; but they now recur in periodic attacks. They subside immediately after a meal, but reassert themselves unfailingly three or four hours later. They are accompanied by heartburn, and often also by waterbrash; subsequently vague impressions of fullness; weight, gurglings, and colicky spasms in the region of the cpigastrium give rise to uncomfortable and distressful feelings of misery. Eructations are frequent, and seem to give such relief that the patient unconscionsly swallows air in order to afford himself the comfort of regurgitating it. Repeated and almost uncontrollable yawning is often experienced. He becomes extremely introspective and nei'vous about himself, is subject to palpitation, sensations of faintness, spasmodic tightness of the chest muscles, and sometimes shortness of breath, for which no adequate reason can be found. When the discomfort has reached its acme, mouthfuls of acrid fluid containing part of the residue of his last meal are not infrequently regurgitated. Vomiting is not common, but, when it occurs, immediate relief ensues; so much so that some patients induce sickness that their comfort may be restored. There is always obstinate constipation. Under treatment the discomforts lessen, and may finally disappear for several months or longer, but are liable to become re-established under the provocation of mental or physical strain. On examination it will be found that there is tenderness in the epigastric region, often specially marked and limited to the right of the middle line, and that the stomach is frequently more or less dilated, splashing sounds being easily elicited in many instances. In doubtful cases part of the stomach contents may be siphoned off and examined chemically, when they will usually present an excess of total acidity, and especially an increase in the free hydrochloric acid. Whenever it is aseertained that the gastric - symptoms follow a course parallel to the mental or moral statebeing, initiated under the influence of anxiety and worry, aggravated by the increase of these conditions, and relieved by their removal-it may be reasonably inferred that the gastropathy is of nervous origin.

The following illustrative cases are selected from recent records, and are related with as much brevity as possible, in order to confirm by clinical data the characteristics of this variety of dyspepsia.

Case I,

Mrs. F. D., aged 42, who had been healthy throughout her life but for two attacks of rheumatism, came complaining of fullness and dragging in the stomach; heartburn coming on three hours after a meal and relieved by food; and a dry and disayreeable mouth with waterbrash from time to time as an mispleasant addition. Her sleep was restless and dreamful, and she was often waked in the early morning by an attack of heartshe was often waked in the early morning by an attack of heart-
buirn and pain in the stomach region. These symptoms had lasted off and on for more than a year, but there were intervals when the discomfort quite disappeared for weeks at a time.
She has neier suffered from liaemorrhage nor vomiting. Her appetite is fairly good. She is of the neurotic true, with a lons tale of woe, and a catalogue of written questions, for eacil of tale of woe, and a catalogue

Her tongue is flabby but clean; the teeth are in sood order the urine is normal; and there are no physical signs in the reflexes are absent. - The stomach is of normal size, but there i marked tenderness to pressure and rectal resistance over the upper area of the epigastrium, particularly on the right side.

This patient was seen again a month later with a record that the heartburn and other symptoms had rapidly disappeared, and that. except for some continusd disturbance of sleep at night, she was practically well. The epigastric tenderness was gone. She has not been heard of since.

B. M., aged 72 , a retired medical man, with a gouty family history, who had spent an active and uninterrupted professional life for over forts years, came complaining of intermittent attacks of pain in the epigastrium lasting for two or three days, and always accompanied by heartburn, eructations, pyrosis,
and disturbed sleep. The discomfort was relieved by food, and and disturbed sleep. The discomfort was relieved by food, and
was in most instances induced by extra work or worry. Polywas in most instances induced by extra work or worry. Poly-
uria was a preceding symptom which always warned him that uria was a preceding symptom which always warned him that
an attack was imminent. His appetite continued good, but he an attack was imminent. His appetite continued good, but he compelled. himself to do with a minimum of food in the hope of lessening the sererity of his uneasiness. He had suffered in
this way since he was between 40 and 50 . He nerer had haemorriage.

On examination, his vessels are thickened and his heart slightly hypertrophied, with a loud second aortic sound. Tho density of the urine is only 1004, and it contains a faint haze of albumen. The lungs are normal. The stomach is dilated, and over the upper end of the epigastrium there is acute pain on deep préssure and such muscular resistance as to make it impossible to determine whether or not there is any perceptible thickening of underlying tissues. The liver is of normal size, and there is nothing else noteworthy in the abdomen. This patient has not been seen again, but from time to time he has reported progress by letter. He rapidly got his attack over, and has only had two very's slight returns, which were speedily has only had two very slight returns, which

According to his last report, he is now bright and active, is sleeping fairly well, has not lost weight, and is free from dyspeptic symptoms.

CASE III.

S. B., aged 56, an Indian merchant, who had suffered from dysentery and malaria, and who had a sastro-enterostomy performed ten years ago because of a duodenal ulcer. At the operation " $a$ mass the size of a walnut" was found at the pylorus, but it was regarded as inflammatory.

He has been travelling recently in the East, and for threo months past has suffered from weight and fullness at the pit of the stomach, with acid eructations and much flatulence, coming on about one hour after meals; and reaching its maximum two hours later. There is uncertainty about the effect of more food, which he is al ways a fraid to take until the discomfort has subsided, but relief is immediately obtained by a dose of sodium bicarbonate. Appetite variable, but seldom gone. This patient is not markedly neurotic, but his knee-jerks are overactive.. He smokes exces.
sively, and there is evidence of vasomotor instability. The teeth are in good order and the tongue is clean. The thoracic organs are in good order and the tongue is clean. The thoracic organs Orer the pyloric region of the stomach there is tenderness on Over the pyloric region of the stomach there is tenderness on
deep pressure, accompanied by muscular rigidity. No "lump" deep pressure, accompanied by muscular rigidity. No "lump" The patient is a spare man, but he has not lost flesh recently.

One month later the discomfort and local tenderness had diminished, and after another month had disappeared. He was sleeping well, vigorously hungry, and taking a carefully arranged mixed diet, withont discomfort from either heartburn or flatulence.

\section{CASE IV}

K. C., aged 62, a hard-working, highly strung, ambitious man. who had never been seriously ili, but had suffered much in later vears from disturbed digestion. Recently his digestive troubles have assumed more definite form, and occni in attacks of some days' duration, which invariably set in after a period of unusual stress, and which are characterized by intense mental depression and restlessness; epigastric fullnes: and pain some hours after food, accompanied by rumbling noises in the stomach and intestines, with constipation, and colourless, offensive stools. Polyuria always precedes these attacks, and although he is hungry he fears to eat on account of the subsequent consequences. He is unable to sleep for any consecutive length of time, and is sure to be awakened between 2 and 3 o'clock in the morning by discomfort in his stomach, which he longs to relieve by an emetic. He has constant hearthurn, accompanied by a disagreeable acrid taste in his mouth. He is distinctly of the neurasthenic type. If examined during an attack, there is tenderness and rigidity in his epigastric an attack, there is tenderness and rigidity in his epigastric region, most marked on the right side; his stomach is dilated, some distension of his colon. "The urine contains indican, but 
neither sugar nor albumen. The heart, though normal in lianeter and without valvular murmur, is often irregular in rhythm and always excitable. The vasomotor system is specially unstable.

'These attacks, though less frequent, still continue, but are amenable to treatment. The patient retains his average weight, and he has never had haematemesis nor melaena.

Case v.

广. K., aged 50, a merchant, active and of spare habit. $\mathrm{He}$ had suffered from indigestion for years, but for many months past his dyspeptic attacks had assumed a paroxysmal character which they did not possess previously. His business had been of late very worrying, and the disturbed state of his digestion had become a nightmare to him, especially as he had been told by a doctor in the country that the most likely explauation of his symptoms was "an ulcer at the outlet of his stomach," for the cure of which he would require to undergo an operation.

His principal complaint was of pain in the stomach, coming oil invariably about 4 o'clock in the morning. During the clay, except tor a sense of fullness some time after meals and unpleasant heartburn, he was comparatively comfortable, but he dreaded the night. Sodium bicarbonate always gave him comfort. He had never vomited, and there was no history of haemorrhage. His bowels were very constipated, and the urine contained an excess of phosphates.

On examination there is tenderness over the pylorus with muscular rigidity, but no definite thickening. The stomach is dilated to the level of the umbilicus, and splashing sounds are at once olutained on succussion. His teeth are in good order, but his throat is granular and his tongue is coated and dry. His organs otherwise are normal.

This patient was not seen again, but several montlis after his visit a friend reported that, though still troubled by his digestion, he was much better and able to sleep the night through.

Miss F. J., aged 57, a spare, active woman, who comes from a neuropathic family but had never been seriously ill herself. She has suffered for years from recurrent attacks of "hunger nain," heartburn, flatulence, mental depression, and borborymi. The stomach discomfort commences about three hours after meals, and is relieved by taking food. Blood has been after meals, and is relieved by taking food. Blood has been seen in the stools repeatedly, but she has a certain amount of epigastrium and dilatation of her stomach exactly as described epigastrium and dilatation of her stomach exactly as described
in the previous cases. She exhibits a certain amount of in the previous cases. She exhibits a certain amount of organic disease.

She was under observation in a nursing lome for some weeks; and before leaving she had been quite comfortable in her digestive organs for a fortnight. I have since heard that she has kept well, and has now resumed the ordinary duties of her life. She is still careful to choose her food and to limit exertion.

Case vir.

R. D., aged 53, a doctor in active practice who had his appendix removed three years ago, and at a subsequent date had a stone taken from his gall bladder. All his life he harl been subject to migraine After his second operation he remained well for several months, then developed attacks of "hunger pain," heartburn, tenderness in the stomach region, chunger pain," heartburn, tenderness

His stomach is not dilated, but in the upper region of the epigastrium there is definite tenderness and muscular resistance epigastrium there is definite tenderness and muscular resistance
to pressure. His urine contains indican, but no albumen or to pressure. His urine contains indican, but no albumen or sugar. He has not experienced any haemorrhage and has never
vomited. He believes himself to be suffering from duotenal vomiter.
nlcer.

His subsequent history, so far as ascertainable, has been one of increased comfort so long as lhe lives " according to rule."

CASE VIII.

A. B., aged 42, a soldier who had served sixteen years abroad, was sent home "supposed to be suffering from duodenal ulcer." He is a spare, sallow, neurotic man, who went through a severe attack of enteric fever in 1901. Until 1906 he was quite well, but then, after a period of overwork, he began to develop intermittent attacks of pain in the stomacl coming on four hours after a meal and relieved by more food. Heartburn is not so much in evidence as in most cases, but off and on it is present, and associated with flatulence and nausea. Occasional blood and mucus are seen in the stools, but there has never been distinctive haemorrhage. The physical signs are precisely those of the other cases in this series, the dilatation of the stomach being of moderate dimensions. He suffers from a blind fistula, being of moderate dimensions. He suffers from a blind fistula, the result of an ischio-rectal abscess some years ago. His teeth
also are very much decayed. His mouth was put right by his lentist, and his sinus cured by a surgeon as the first step in his treatment.

Thereafter his progress, though occasionally interrupted by a slight return of "hunger pain" and stomach dis- comfort, was satisfactory, and now, after a little more than a year at home, he has been free from symptoms for some months and has put on weight. He has rejoined his regiment.

Case ix.

C. H., aged 33, a clergyman, hard-worked and active. Had his appendix removed a little more than a vear goo ever since, disturbed digestion: acute heartburn and pain three or four hours after food, relieved by the next meal ; fluter cin vomiting. The physical signs are a repetition of those already vomiting. The physical signs are a re
given, but with no stomach dilatation.

When seen four months later he was much better than at any time since his operation, and nothing abnormal could be detected on local examination.

\section{Case $\mathrm{x}$.}

Mrs. A. L., aged 34. A healthy woman, who had suffered whén abroad five years previously from obstinate dysentery. During her first pregnancy she had considerable trouble from heartburn and nausea, and on three or four occasions had attacks of acute pain which she was told were gastralgic. attacks of acute pain which she was told were gastralgic. After the birth of her child she experienced repeated attacks of the old gastric pain before meals, with heartburn and fiatulence
lasting for two or three days. In addition she had several lasting for two or three days. In addition she had several intermittent attacks of more acute pain, accompanied loy and colourless stools, strongly suggestive of gall colic. Three and colourless stools, strongly suggestive of gall colic. Three
months after her confinement her gall bladder was opened, months after her confinement her gall bladder was opened,
and ten small stones were removed. She made an excellent recovery, but after two months she developed " hunger pain." heartburn, and distension. Her discomfort came so frequently during the night that she always had at her bedside a supply of dry biscuits, munching one or two of which afforted her relief.

A year later she was very well and had no digestivo troubles. The following year a second pregnancy occurred, and now, two months after her last continement, the gastric troubles have again asserted themselves as before, and are associated with tenderness over the pyloric region and gastric dilatation. Under treatment she has regained complete comfort.

CASE XI.

C. G., aged 51; a man of active habits who, until four years previously, had never been ill. He then began to suffer from attacks of pain which were thought to be due either to cholecystitis or duodenal ulcer. He was sent to Carlsbad avd other: health resorts, but he got no better. Eventually his abilomel was opened; no gall stones were found, and there was no ulcer, but there were many adhesions round the pylorus and duodenum, also "a mass of plands at the head of the pancreas and at the root of the mesentery," the densest adhesions being at the root of the mesentery, the densest adhesions beins round it. The adhesions were divided, but no gastlo-enterostomy was done, and the patient made an uneventful recovery. Subsequently to his operation, though he had no return of the acute pain, which simulated gall colic, his digestion became again troublesome, and has now assumed the type of the others of this series of cases-heartburn and pain some hours after
meals, at once relieved by a bismuth and soda mixture which he meals, at once relieved by a bismuth and soda mixture which he
always keeps by him; epigastric tenderness; dilatation of the stomach; broken sleep; intervals of comparative comfort vigorous appetite; no sickness. His urine contains an excess of phosphate, and gives a positive pancreatic reaction.

Under treatment he improved considerably, his attacks being both less frequent and less severe, but in a minor degree they were liable to return upon slight provocation. The neurotic element in his case was very pronounced and interfered with any permanent stability of health.

CASE XIr.

E. D., ageil 43, a gouty man, who had always lived well and taken too little exercise. For about three years he had suffererl from acidity and pain in the stomach an hour or more ufter n:eals, with fullness, flatulence, and waterbrash. The pain is temporarily relieved by one or two soda-mint lozenges, but temporarily relieved by one or two soda-mint lozenges, but lecur's until it is more permanently overcome by the following meal. On examination the same local signs are present as in the other cases, the tende

After some months of treatment the symptoms disappeared, aud when he was last seen there was no epigastric tenderness, the stomach was of normal si\%e, and he appeared to be in fairly good health.

\section{CASE XIIr.}

F. B., aged 41 , a spare man of sallow complexion, who tad lived much abroad and who had had repeatar attacks of malaria in East Africa, the last being in 1935 . Since then his digestion in East Africa, the last being in 1935 . Since then his digestion. had been troublesomie and he had developed the precise train of symptoms which these cases illustrate. The heartburn bas
been, in this case, specially severe, and he has been afraid to been, in this case, specially severe, and he has been afraid to eat; espite an urgent appetite, because of the misery the
acidity causes him. He has had no haemorrhage and only very 
occasional vomiting. The epigastric tenderness is pronounced. The stomach is dilater to the level of the umbilicus, and four hours after food there is still a loud and perceptible succussion splash. He has been told that he is suffering from a "peptic ulcer." A year or more ago he underwent three months' treatment by massage, vegetarian diet, rest, etc., but there was no manifest improvement.

At the end of six months he was much better and the dilatation of his stomach had disappeared. He was sleeping perfectly at night, had put on weight, and was much happier about himself.

\section{CASE XIV.}

Miss P., aged 42, for many years had suffered from palpitation, flushings after food, with pain, heartburn, waterbrash, and flatulence coming on between meals. Occasional vomiting and sometimes lienteric diarrhoea. She is never without sodium bicarbonate, which she depends upon to relieve her gastric symptoms. She is a highly-strung woman whose life has been full of anxieties. She sleeps badly at night and suffers much from vertical heaidaches. Her family history is tainted with neuroses and mental affections through several generations. The physical signs correspond to those already related, but in addition she has intermittent polyuria, a very loose right kidney, and extraordinarily accentuated knee-jerks with complete absence of plantar reflexes. There is a haemic murmur over the base of the heart, but otherwise the organs are normal.

Improvement in this case was slow, and relapses were frequent, but gradually she regained some degree of nerve stability and coincidently with this her gastric discomforts diminished. She got sufficiently well to marry some months ago and to go to California where she now lives.

\section{CASE XV.}

R. H., aged 50, a robust, active man of the gouty type, who hal never been ill except for an attack of enteric fever when he was 20 years of age. Ten months ago he first suffered from indigestion, and it had recurred from time to time ever since. His doctor believed him to be the victim of duodenal ulcer, and his doctor believed him to be the victim of duodenal ulcer, and wis symptoms and physical signs were distinctive enongh to warrant such a provisional diagnosis. The question of operation was considered and deferred, and improvement ensued to
such an extent that for some months he remained well and such an extent that for some months he remained well and gained over a stone in weight. Under the stress of a litigation in which he has been recently engaged he has again experienced a recurrence of heartburn, flatulence, waterbrash, and constipation, exactly as before, but in milder degree. The discomfort comes on between meals, and he longs for his nex meal because of the temporary comfort it gives him. On siderable localized tenderness in the epigastrium.

From this attack he again in time recovered, and since May of 1910, when he was reported to be "very well if only he is careful," I have not heard of him.

\section{CASE Xvi.}

H. M., aged 49, a pale, spare man of scientific pursuits, who leads an almost entirely sedentary life. He has had three mild attacks of pleurisy, but otherwise has escaped serious illness. For some years he has been subject to mild attacks of indisestion, but in the past five months these have assumed more formidable and defined outlines.

His story is now a repetition of the others-" hunger pain" relieved by food, acute heartburn, ejigastric discomfort, and constipation. Between the attacks he is quite comfortable, but lie has come to realize that they are readily induced by overstrenuous work or worry. During an attack the usual physical signs of tenderness to right of the epigastrium and distended stomach are present; in the quiescent intervals they completely disappear. Beneath an elaborate mechanism of gold crowns and bridges there is an active prorrhoes of which he is completely unaware. A surgeon who was consulted diagnosed the condition as one of undoubted duodenal ulcer, for which no the condition as one of undoubted duodenal ulcer, for which no
permanent relief was likely to be obtained except by operation.

Since the mouth has beon attended to by his dentist and his habits of life have been altered, this patient, under a suitable dietetic and medicinal régime, has manifestly im. proved, and now only occasionally experiences mild reminders of his gastric troubles.

\section{Case Xvir.}

M. B., aged 44, a soldier, had always enjoyed good bealth until he contracted enteric fever in Ladysmith. Subsequently he suffered from dysentery for close upon two years. Early in 1909, while stationed in India. he began to expe-
rience trouble with his-digestion, which gradually assumed rience trouble with his -digestion, which gradually assumed
the neurotic type, and he was sent home, with a provisional the neurotic type, and he was sent home, with a provisional attacks are paroxysmal and are characterized by " hunger pain," heartburn, pyrosis, distension and constipation, with occasional vomiting, from which he obtains immediate relief. There is no history of haemorrhage. During an attack it is easy to demonstrate the usual tenderness and muscular resistance in the epigastrium with moderate dilatation of the stomach. His nervous system is feeble, and he suffers from a bewildering variety of neurasthenic miseries which are troublesome to treat. He saw a surgeon, who consented to his giving medicine a chance, but warned him that an operation was an ultimate possibility.

Over many months he battled with his infirmities, but eventually he began to mend, to put on weight, and to feel himself energetic enough for a fair day's exercise: After having been, so far as subjective sensations an 1 objective signs are concerned, for between three and four months quite well, he returned to his regimental duties in India, since which time he has not been hesrd of.

\section{CASE Xvirr.}

A. C., aged 67, a retired officer, who had been healthy all his life but for an occasional attack of gout, and, in recent years, one or two mild seizures which he had been told were aginal. For about a year he had suffered from gastric symptoms, which conformed in all respects to the other cases of this series, but in addition he was steadily losing weight. This fact, combined with the patient's age, suggested very naturally to his home doctor the possibility of early malignant disease at his pylorus, and this suggestion was supported by the extreme rigidity of his right rectus muscle and the acute localized tenderness over the pyloric region. In addition, his family record was not free from a malignant taint. On examination the stomach was confrom a malignant taint. On examination the stomach was considerably dilated, and splashing sounds were easily produced: He continued to suffer from these gastric attacks for over three years after he was first seen, but with increasingly long intervals
between them. During part of that time he was living under the strain of severe domestic anxiety, which was followed by. a great sorrow. When this had passed his gastric attacks became less severe, as well as less frequent. He went for two seasons to Wiesbaden, and seemed to derive benefit from the cure."

A few weeks ago he reported that he had not experienced any gastric attack for more than eighteen months, and had put on $17 \frac{1}{2} \mathrm{lb}$. in weight.

\section{CASE XIX.}

H. S., aged 53, a gouty man, of very active habits, who had all his life "done himself well.", $\mathrm{He}$ had never been seriously ill, and had always had an excellent appetite. His attacks of indigestion dated back for two or three years, but of late indigestion dated back for two or three years, but of late by waking him from sleep in the early morning. Each attack is characterized by " hunger pain" and heartburn, and is so is characterized by " hunger pain" and heartburn, and is so once to toast or biscuits on the first symptom of discomfort. He presents the usual physical signs during a seizure, but between whiles there is no tenderness even on the deepest pressure, and his stomach is of normal size. His liver dullness is diminished and the urine is persistently of low specific gravity with an occasional haze of albumen. He is extremelv neurotic, and the pain is always accompanied by serious mental depression and irritability. His most ominous attack seized him at 3 o'clock one morning, and was accornpanied by copious haematemesis and subsequ, ant maccornpanied by copious haematemesis and subsequent melaena. But as a possible explanation it must be added that during the previous day he had overtired himself by continuous and extreme exertion, in the evening had indulged in an aldermanic dinner, abdominal kneadings and contortions which a Swedish professor had taught him to believe would prevent stomach troubles during the night. He recovered completely, and had no recurrence of bleeding.

When last seen, in 1910, he had been living a much less active life, and his attacks of pain had recurred very seldom. At that date he had been quite free for upwards of three months.

\section{CASE XX.}

Mrs. L., aged 54, for about a rear had experienced discomfort, coming on some hours after each meal-flatulence, constipation, pain at pit of stomach, and heartburn, immediately, though only temporarily, relieved by sal volatile and sodium bicarbonate. She had steadily lost weight. There had never bicarbonate. She

The physical signs are those of the preceding cases, and, in addition, she has her right kidney loose. There is a record of malignant disease through two generations.

As improvement under medical measures had been disappointing, she was advised to have an exploratory operation, $\mathrm{n}$ the belief that an early malignant growth might be the explanation. This was performed, but nothing was found to explain the symptoms, which recurred, though in minor degree, after her convalescence.

Ultimately she responded to treatment, and has now been, for several years, quite well.

From a consideration of these cases there is abundant confirmation of the statement that this type of dyspepsia is frequently mistaken for duodenal ulcer. And there are many similarities in the symptomatology of the two conditions to excuse confusion. Indeed, it may be asserted, with a fair degree of certainty, that differentiation is not always possible. If this be admitted, there is good reason for 
a plea against operative interference until medical measures have had a sufficient chance of proving that they are of no avail in clearing up the symptoms. It is possible that this form of dyspepsia is often the forerunner of duodenal ulceration, but, in that event, may its early reeognition and suitable treatment not be the means of arresting the functional disease and of thereby saving a certain number of sufferer's from the anxiety and risk of a surgical operation? The contention that immediately a chronic dnodenal ulcer is diagnosed it must, without loss of time, be treated surgically cannot, in the face of cases such as the foregoing, be maintained. Because they indicate that the diagnosis of cbroric ulcer of the duodenum is not so easy and certain as some authorities would have us believe, and, further, they go a long way towards proving that if, in some instances, the symptoms are really due to nlceration, they are capable of relief or cure by medical methods. It may be held that this type of dyspepsia is in no respect, except in regard to the greater intensity of its symptoms, different from the "acid dyspepsia" which we are accustomed to differentiate from the simple atonic variety of the disorder. But even if it be adnitted that it may be nothing more than an aggravated form of what Robin has called hyperfunctional activity, it yet remains true that it possesses characteristics which mark it off as having attained an individuality with such close analogies to the symptoms produced by ulcoration in the neighbourhood of the pylorus as to justify its delimitation as a clinical entity.

In neurasthenic patients there is a hypersensitiveness of all the tissues. This is participated in by the gastrointestinal mucous membrane, and probably permits gastric juice of normal acidity to produce symptoms similar to those described as due to hyperchlorhydria. Some authorities are of opinion that no such condition as hyperchlorhydria really exists, and that an ordinary "acid dyspepsia " due to an excessive secretion of normal gastric juice is capable of causing most of the symptoms ascribed somewhat indiscriminately to hyperchlorhydria and duodenal ulcer. This opinion is strengthened by the fact that estimates of free hydrochloric acid have proved inconsistent, not only as between case and case, but also in the course of repeated investigations of the same patient. The combination of a super'sensitive mucous membrane with an excess of gastric juice must tend to aggravate the subjective phenomena, and make them, by their intensity, the more readily mistaken for an organic lesion.

It should be observed also that in most of the cases here recorded there is a history of ill-defined digestive disturbance lasting over a longer or sborter time before the definitive picture of neurotic dyspepsia has become established. Is it not conceivable that a toxaemic condition evolving from this disturbed state of the gastro-intestinal secretions and acting upon an unstable nervous system may, in the case of neuropathic individuals, have the power of elaborating this particular type of digestive disturbance? And nay the primary departure from health not be inferentially predicated, if it be admitted that in a person of neurasthenic type the intestinal nucous membrane, on account of its hypersensitiveness, is more liable to the incursion of precocious micro-organisms than in an individual of stable nerve equilibrium? The true history may, in some instances, be a graclual progression from a simple acid dyspepsia, onwards through this type of nervous dyspepsia to the ultimate development of an established nlceration. T'here is, in this event, ample reason to minimize the risk of edror by establishing the intermediate condition on a basis to admit of its recognition and justify its treatment by medical measures which may prove to be curative. Its occurrence in persons of neuropathic type, who are at or past middle life; the intensity of the heartburn by which it is accompanied; the relief which is afforded by alkalis or by fresh supplies of food; the late period after the ingestion of a meal at which the symptoms first checlare themselves; the preservation of an active appetite; the localized epigastric paiu ; the dilatation of the stomach; and the absence of haemorrhage, are leading differential points of which the foregoing cases are illustrative. They also go to show that treatment by diet and medicine is capable of effecting marked amelioration and, so far as the histories lead us, permanent cures in some instances where the diagnosis of cluodenal ulcer had been arrived at and operation adrised as the only method of treatment likely to be successful. The following symptoms have been recorded as pathognomonic of duodenal ulcer: "Hunger pain" coming on some hours after a meal and relieved by more food; localized tenderness to the right of the epigastrium; early dilatation of the stomach disturbed sleep, and melaena. On the strength of this evidence alone some surgical authorities have contended that operation is not only justifiable but imperative. But in this series of cases all these symptoms have presented themselves in each instance, with the one notable exception of melaena. And that even this occurrence is liable to misinterpretation may be assumed from the record of Case XIx, where it is at least a warrantable hypothesis that the bleeding was the result of hepatic cirrhosis, and was excited by indiscreet manipulation of the abdomen aiter a full meal taken when the physical energies were mush exhausted by a long day of hard exercise. Excessive acidity, though undoubtedly a concomitant of duodenal ulcer, is also admittedly a manifestation to which patients of a certain type are peculiarly liable; and this form of neurotic dyspepsia, more than likely, may be a mere manifestation of an acid dyscrasia of which ulceration on one or other side of the pylorus is nothing more than a late.symptom. Post.mortem evidence is not wanting to prove that duodenal ulcers are capable of healing without the aid of a surgical operation, and it is well known that many operations undertaken for the cure of apparent ulceration of the duodenum have proved the diagnosis to be erroneous. It is also a point of importance as bearing upon the dyscrasic theory, that "once having had a duodenal vilcer does not secure the patient from having a second," so that, even in cases of proved ulceration, operation may be only temporarily aneliorative. The symptom of "hunger pain" has been too strongly insisted upon as being pathognomonic of ulceration, and hyperchlorhydria, with " which it is associated, has been stated to be the direct cause upon which it depends. It has even been asserted that "recurrent severe hyperchlorhydria is duodenal ulcer," and in one well-known surgical textbook the author's state that, " in our experience, hyperchlorhydria has never existed without ulcer in the stomach, or duodenum, or both." If this is true, then these cases go to prove that it nust be no less true that improvement or recovery can take place by medical measures, and that a gastro-enterostomy is not the one and only means of salvation. Another eminent surgeon says: "I continually operate upon the strength of the history alone, and as often do I demonstrate the existence of a chronic ulcer as the canise of the symptoms," but on clinical evidence it may be doubted whether such wholesale operative interference is to be commended. There is ample evidence for believing that all the symptoms described as characteristic of duodenal ulcer may be reproduced by a simple functional disorder of the stomach, whether it be called neurotic dyspepsia, hyperchlorhydria, or what not.

The treatment of this variety of dyspepsia demands carc as to diet, exercise, and habits of life generally. It is essential to the attainment of a satisfactory result that the patient should be somewhat self-denying and willing to co-operate with the physician in carrying out over a sufficient length of time all the details of a well-considered course of management. If his illness has lasted over any prolonged period, the misery it has caused is worth a se ious effort to get rid of ; and if, as is not unlikely, this form of dyspepsia is a stage on the road to ulceration, no preventive means that can be adopted are too elaborate to effect an escape from the risks of such a culmination. Moreover, it is only by a process of careful observation and supervised treatment that, the question of the need for surgical intervention can be wisely settled.

The plan of treatment which I have found to answer well in many, though not in all, cases, may commend itself to you as worthy of trial before you are driven to the conclusion that your patient has no hope of improvement or recovery except through the medium of the surgeon's knife. It goes without saying that, however we treat his disorder, we must never lose sight of the patient ior be oblivious to his idiosyncrasies.

All treatment should aim in the first place at being sedative not only to the stomach but to the whole nervous system. In cases of moderate severity the daily routine of life need not be se iously interfered with. A suitable regu- 
lation of the dict and restriction of mental and physical effort must, however, in every instance, be insisted upon. If the symptoms are urgent and the patient wishes to get the most speedy and permanent benefit, he should consont to spend a week entirely in bed, and preferably in a nursing home away from the usual domestic environment. During this resting period his routine ought to be somewhat as follows: In the early morning a tumblerful of water as hut as can be borne, to which a small teaspoonful of citrate of potash has been added, should be sipped slowly. This should be followed by a hot bath at from $98^{\circ}$ to 102 F., in which immersion may continue for from cight to ten minutes. After vigorous friction with a rough towel, he must return to bed and to 'reakfast, which should consist of café an lait or milk tea, sweetenell with saxin ; ordinary toast and caseoid or other starchless bread in cqual proportions, with abundance of butter; bacon, tongue, cold ham, eggs, coll game, or white fish. About ten o'clock he should be massaged for an hour, and thereafter remain for another hour quietly at rest. Luncheon, about 1 o'clock, should consist of a grilled chop or steak, or a cut from a joint, cooked green vegetables, a compôte of fruit au naturel or sweetened with saccharine, a biscuit or oatcake with butter and a morsel of cheese, an alkaline table water, to which may be added, if desired, an ounce of whisky or brandy. In cases where indican in the urine and offensive stools point to putrefactive changes in the intestine, the cheese should be of the "soured-milk" variety. A short sleep after luncheon is advisable. At 4.30 a cup of China tea or of cocoa infused from the nibs, sweetened with saxin and enriched with cream, will prove grateful, and may be accompanied by crisp dry toast and butter. A visit from one or two intimate friends should be arranged for the interval between tea and dinner. The patient should dine about 7 , and the mcal should consist of a small cupful of clear consommé, white fish, chicken or game, purée of vegetables, a simple omelette, and one or two glasses of a light Moselle or hock if desired. "Akoll" or de Voebt's biscuits shonld be taken with luncheon and dinner rather than ordinary bread. Before retiring for the night at 10 o'clock, the abilomen should be gently massaged for a quarter of an hour, and the morning tumblerful of hot alkaline water ought to be repeated. For another week this plan should be continued, but with the difference that during the afternoon of each day a drive in an open carriage, followed by a short walk, is desirable. Thereafter a resumption of the ordinary duties of life may be permitted, but the engagements of every day should be limited, and the same diet plan continued until for at least a fortnight there has been no recurrence of stomach symptoms.

Medicinally attempts should be made: (a) To control the glandular secretions of the stomach and lessen the hyper'sensitiveness of its nucous membrane; (b) to counteract hyperacidity when it arises; $(c)$ to overcome constipation. These indications may be met by a variety of drugs. The following combinations are the outcome of many experimental efforts in this direction, and I have found them to effect the desired result in a large proportion of cases

(ii) Solution of atropia, solution of hydrochlorate of morphine, solution of adrenalin chloride, and spirits of peppermint in suitable doses to make up 1 drachm. To be diluted with one tablespoonful of water and taken a quarter of an hour before breakfast, luncheon, and dinner.

(7) Magnesinm carbonate, sodium bicarbonate, bismuth salicylate, and ginger. To be dispensed in a cachet and taken whenever heartburn declares itself. A second cachet may bo taken after an hour if the first does not succeed in overcoming the acidity.

(c) Acetic extract of colchicum, alöin, capsicin, and extract of rhubarb. 'To bo made into a pill and taken every alternate evening before dinner.

Carlsbad salts or 'Kutnow's powder in a suitable dose is useful before the morning tumblerful of hot water if the above pill prores inefficient.

After the gastric symptoms have disappeared and the digestion has again become normal, the diet may be modified, especially in the direction of including a larger amount of farinaceous food with a limited quantity of sugar, and some advantage will accrue from suitable tonics. These mist vary according to circumstances, but in many instances the indications will be met by such a combination as this: Carbolic acid,.valerian, sodium arseniate, and cannabis ndica. To be dispensed in a capsule, and taken three times a day after meals.

The morning tumblerful of hot alkalinized water onght to be continued as a matter of daily rontine. Sugar and starches should always be taken in moderate quantity. A Turkish or electric-light bath once in eight or ten days, followed by general massage for twenty minutes, is a desirable practice in many cases.

It is important to secure, as far as possible, a clean condition of the mouth. To this end, all stumps and carions teeth ought to be removed, and the buccal cavity rinsel out twice or three times a day with a solution of suitable strength of glycothymolene, listerine, carbolic acid, or other reliable antiseptic.

\section{RADIUM IN MALIGNANT DISEASE AND} VARICOSE UICERATION.

[With Special Plate.]

By T. ROSS MACDONALD, M.B., C.M.

THE exact value and position of radium as a therapentic agent will, of course, only be defined when all the conditions which influence its activity have been carefully studied. Prominent among these conditions must necessarily be the amount or dose to be employed and the length of its application. Similar questions, no doubt, arise in connexion with every substance advanced as is remedy for disease, but in the case of radium they are complicated by a severely practical relation-namely, that of oxpense. The market value of radium is so enormous and the supply is so limited that in the very nature of the case there is a pressing temptation to be content with a minimum amount. But it is at least possible that whe small quantities fail larger doses would be successful; and it is only by testing this question that an assurance of tho real value of radium can be obtained. Having harl considerable opportunities of observing the effects of different doses, I have satisfied myself that in many cases the maximum benefit is only to be obtained by the use of relatively large amounts and by the application of these over relatively prolonged periods of time. Under these conditions I liave certainly witnessed many very striking results, and some of these I propose briefly here to put on record. The selection is limited for the most part to cases which, owing to the courtesy of Sir W. Watson Cheyne, I have been able to observe and to treat in King's Collego Hospital. The circumstances therefore guarantee certainty in diagnosis, while the illustrations of the facts before anil after treatment carry their own convincing message, and this message I could abundantly confirm from my own private note-books.

At present, at all events, the use of radium in malignant disease is almost or aitogether confined to inoperable cases, and whether there will or will not be any advance from this position it is impossible to say. But there is one aspect of the subject which I believe to be worthy of careful study, aid that is the use of radium in conjunction with operation and for the purpose of preventing recurrences. The amount of clinical raterial at my disposal on this point is too limited and the length of time since the observations were instituted is too short to justify any unqualified statement, but I am sure the question is one worthy of attention, and $I$ have reason to believe it is also of great practical importance.

In reference to the amount of radium employed, I mav say that I generally use tubes containing 250 to $300 \mathrm{mg}$. of pure radium bromide, and $I$ am satisfied that in great measure it is on such relativcly large amounts that the best results depend. Of course the initial expense is enormous, the above-named quantity of pure rar?imm bromide being worth nearly $£ 5,000$, but. if inoperable nalignant diseas can be cured or even greatly relieved, the gain manifestl: counterbalances the outlay. The question is not one of market value, but of therapeutic value, and if this latter. is established we must hope that by some means or othe: the use of the remedy will be brought within the range of all sufferers. Of the therapentic value, the following 